\title{
Fatty acids acutely enhance insulin-induced oxidative stress and cause insulin resistance by increasing mitochondrial reactive oxygen species (ROS) generation and nuclear factor- $\kappa$ B inhibitor (IKB)-nuclear factor- $\kappa B(\mathrm{NF} \kappa \mathrm{B})$ activation in rat muscle, in the absence of mitochondrial dysfunction
}

\author{
R. Barazzoni • M. Zanetti • G. Gortan Cappellari • \\ A. Semolic • M. Boschelle • E. Codarin • A. Pirulli • \\ L. Cattin • G. Guarnieri
}

Received: 24 August 2011 /Accepted: 3 November 2011 /Published online: 13 December 2011

(C) Springer-Verlag 2011

\begin{abstract}
Aims/hypothesis Insulin effects reportedly involve reactive oxygen species (ROS) and oxidative stress in vitro, but skeletal muscle oxidative stress is an emerging negative regulator of insulin action following high-fat feeding. NEFA may enhance oxidative stress and insulin resistance. We investigated the acute impact of insulin with or without NEFA elevation on muscle ROS generation and insulin signalling, and the potential association with altered muscle mitochondrial function. Methods We used hyperinsulinaemic-euglycaemic clamping, 150 min, without or with lipid infusion to modulate plasma NEFA concentration in lean rats.

Results Insulin and glucose (Ins) infusion selectively enhanced xanthine oxidase-dependent muscle ROS generation. Ins with lipid infusion (Ins+NEFA) lowered whole-body glucose disposal and muscle insulin signalling, and these effects were associated with high muscle mitochondrial ROS generation and activation of the proinflammatory nuclear factor- $\mathrm{KB}$ inhibitor (IKB)-nuclear factor- $\mathrm{KB}(\mathrm{NF} \kappa \mathrm{B})$ pathway. Antioxidant infusion prevented NEFA-induced systemic insulin resistance and changes in muscle mitochondrial ROS generation, IKBNFKB pathway and insulin signalling. Changes in insulin
\end{abstract}

R. Barazzoni $(\bowtie) \cdot$ M. Zanetti $\cdot$ G. G. Cappellari $\cdot$ A. Semolic

M. Boschelle $\cdot$ E. Codarin · A. Pirulli $\cdot$ L. Cattin $\cdot$ G. Guarnieri

Clinica Medica, Department of Medical,

Surgical and Health Sciences, University of Trieste,

Ospedale Cattinara, Strada di Fiume 447,

Trieste, Italy

e-mail: barazzon@units.it sensitivity and signalling were independent of changes in mitochondrial enzyme activity and ATP production, which, in turn, were not impaired by changes in ROS generation under any condition.

Conclusions/interpretation Acute muscle insulin effects include enhanced ROS generation through xanthine oxidase. Additional NEFA elevation enhances mitochondrial ROS generation, activates IKB-NFKB and reduces insulin signalling. These alterations are not associated with acute reductions in mitochondrial enzyme activity and ATP production, and are reversed by antioxidant infusion. Thus, NEFA acutely cause systemic and muscle insulin resistance by enhancing muscle oxidative stress through mitochondrial ROS generation and I $\kappa \mathrm{B}-\mathrm{NF} \kappa \mathrm{B}$ activation.

Keywords Fatty acids · Inflammation · Insulin · Insulin resistance $\cdot$ Mitochondria $\cdot$ Oxidative stress

$\begin{array}{ll}\text { Abbreviations } \\ \text { AA } & \begin{array}{l}\text { Antimycin A } \\ \text { AKT }\end{array} \\ & \begin{array}{l}\text { V-akt murine thymoma viral oncogene } \\ \text { homologue } 1\end{array} \\ \text { CCCP } & \text { Carbonyl cyanide } m \text {-chlorophenyl hydrazone } \\ \text { GM } & 8 \mathrm{mmol} / 1 \text { glutamate, } 4 \mathrm{mmol} / 1 \text { malate } \\ \text { GS } & 4 \mathrm{mmol} / 1 \text { glutamate, } 8 \mathrm{mmol} / 1 \text { succinate } \\ \text { GMS } & 4 \mathrm{mmol} / 1 \text { glutamate, } 2 \mathrm{mmol} / 1 \text { malate } \\ & 10 \mathrm{mmol} / 1 \text { succinate } \\ \text { GSH } & \text { Reduced glutathione } \\ \text { GSSG } & \text { Oxidised glutathione }\end{array}$




\begin{tabular}{|c|c|}
\hline HRP & Horseradish peroxidase \\
\hline $\operatorname{IkB}(\alpha)$ & Nuclear factor- $\mathrm{KB}$ inhibitor $(\alpha)$ \\
\hline Ins & Insulin and glucose [infusion] \\
\hline NAC & $N$-acetyl cysteine \\
\hline NFKB & Nuclear factor- $\mathrm{kB}$ \\
\hline PCM & $\begin{array}{l}50 \mu \mathrm{mol} / \mathrm{l} \text { palmitoyl-L-carnitine, } 2 \mathrm{mmol} / \\
1 \text { malate }\end{array}$ \\
\hline PM & $5 \mathrm{mmol} / 1$ pyruvate, $5 \mathrm{mmol} / 1$ malate \\
\hline PPKM & $0.25 \mathrm{mmol} / 1$ pyruvate, $12.5 \mu \mathrm{mol} / 1$ palmitoyl- \\
\hline & $\begin{array}{l}\text { L-carnitine, } 2.5 \mathrm{mmol} / 1 \alpha \text {-ketoglutarate, } \\
0.25 \mathrm{mmol} / 1 \mathrm{malate}\end{array}$ \\
\hline $\mathrm{P} / \mathrm{T}$ & Phosphorylated/total [ratio] \\
\hline ROS & Reactive oxygen species \\
\hline $\mathrm{S}$ & $10 \mathrm{mmol} / \mathrm{l}$ succinate \\
\hline SR & $20 \mathrm{mmol} / 1$ succinate, $0.1 \mathrm{mmol} / 1$ rotenone \\
\hline
\end{tabular}

\section{Introduction}

Insulin has been shown to enhance reactive oxygen species (ROS) generation and oxidative stress in adipose and liver cells in vitro, and these effects are reported to be directly involved in the stimulation of insulin signalling by inactivation of protein phosphatases [1-3]. A more recent study also found that mice lacking the major antioxidant enzyme glutathione peroxidase have high muscle oxidative stress and are less, rather than more, insulin resistant than wild-type counterparts [4]. In contrast with the above observations, oxidative stress markers are elevated in insulin-resistant obese and type 2 diabetic individuals $[3,5,6]$, and oxidative stress is reported to occur in, and directly contribute to, fatinduced insulin resistance in skeletal muscle in high-fat-fed rodents [7]. Available data also indicate that oxidativestress-induced insulin resistance involves nuclear factor- $\mathrm{KB}$ $(\mathrm{NF} \kappa \mathrm{B})$ nuclear translocation after nuclear factor- $\mathrm{KB}$ inhibitor $\alpha(\operatorname{I\kappa } B \alpha)$ phosphorylation and degradation [8]. The potential involvement of chronic NEFA elevation in highfat-diet-induced changes in muscle oxidative stress, inflammation and insulin action is suggested by in vitro studies [9, 10], and fatty acids are also reported to induce insulin resistance in vivo $[11,12]$. In addition, the onset of oxidative stress and inflammation during chronic high-fat or highenergy feeding has been reported to lower skeletal muscle mitochondrial oxidative capacity [13, 14], and this alteration could contribute to insulin resistance through impaired muscle lipid oxidation [15]. The in vivo effects of NEFA on muscle oxidative stress, inflammation and mitochondrial function as well as the potential pathways involved and their associations with insulin signalling remain, however, undefined.

In the current study we sought to determine the potential interactions between insulin and NEFA in the regulation of muscle ROS generation and insulin sensitivity in vivo. The impact of physiological insulin elevation on muscle ROS generation from different mitochondrial and nonmitochondrial sources was investigated using the hyperinsulinaemic-euglycaemic clamp technique. The potential additional impact of concomitant NEFA elevation on muscle ROS generation, the ROS-activated I $\mathrm{KB}-\mathrm{NF} \kappa \mathrm{B}$ proinflammatory pathway and insulin action was also investigated in the presence and absence of antioxidants. Parallel changes in muscle mitochondrial function were determined in order to assess their response to acute changes in tissue redox state and their potential association with changes in insulin sensitivity.

\section{Methods}

Animals and experimental protocol

The experimental protocol was approved by the Committee for Animal Studies at Trieste University. Seventy 12-weekold male Wistar rats were purchased from Harlan-Italy (San Pietro al Natisone, Udine, Italy) and kept for 2 weeks in the Animal Facility of the University of Trieste in individual cages with a $12 \mathrm{~h}$ light-dark cycle (06:00 hours/ 18:00 hours). Starting 3 days before the experiments, $4 \mathrm{~h}$ tail-restraint periods were performed each day [16] by pulling the tail through a tail-sized hole in the cage and securing it to a horizontal Plexiglass support. Animals had free access to water and standard rat chow (Harlan 2018, $14.2 \mathrm{~kJ} / \mathrm{g}$, Harlan, San Pietro al Natisone, Italy). To minimise potential stress responses and eliminate any differential response among groups, identical restraining training and study protocols were applied to all animal groups. No significant changes in blood glucose, a relevant stress marker, were observed following the $4 \mathrm{~h}$ adaptation periods (data not shown).

On the morning of the infusion day, catheters were placed percutaneously into one tail vein and one tail artery under local lidocaine anaesthesia [16], and the tail was then secured as described above. Food was withdrawn after catheter placement and animals were kept in this position for $4 \mathrm{~h}$ before the infusions were started. Immediately before the start of infusions $(t=0), 250 \mu \mathrm{l}$ blood samples were drawn from the artery for basal measurements of blood glucose (Accu-Chek, Roche Diagnostic Corporation, Indianapolis, IN, USA) or stored at $-80^{\circ} \mathrm{C}$ for measurement of insulin and NEFA. Rats were randomly assigned to undergo one of the following $150 \mathrm{~min}$ infusion protocols: (1) control, $\mathrm{NaCl}$ infusion $(n=18)$; (2) insulin and glucose (Ins), hyperinsulinaemic-euglycaemic clamp with insulin infusion (Humulin R; Eli Lilly, Indianapolis IN, USA) at $5 \mathrm{mU} \mathrm{kg}^{-1} \mathrm{~min}^{-1}$ and variable $20 \%$ glucose to maintain near-basal blood glucose 
concentration ( $n=20)$; (3) Ins and lipid (Ins+NEFA), as above with additional infusions of a lipid emulsion (Ivelip $20 \%$, Clintec Parenteral, Maurepas, France) at $600 \mu \mathrm{l} / \mathrm{h}$ and heparin (20 U/h; Epsoclar, Biologici Italia, Novate Milanese, Italia) aimed at elevating circulating NEFA ( $n=20)$; (4) Ins+NEFA and $N$-acetyl cysteine (NAC; Ins+NEFA+NAC), as described above but with the addition of NAC (Sigma, St Louis MO, USA) $(n=10)$. An initial priming dose $(75 \mathrm{mg} / \mathrm{kg}$ ) was injected in the tail artery $20 \mathrm{~min}$ before the infusion, and continuous $\left(25 \mathrm{mg} \mathrm{kg}^{-1} \mathrm{~h}^{-1}\right)$ i.v. infusion was performed during the euglycaemic clamp. Selection of NAC dose and delivery was based on literature review [17]. Heparin infusion identical to that in the Ins+NEFA group was performed in both other experimental groups. In all animals, blood glucose was monitored every $15 \mathrm{~min}$, and glucose infusion rates were adjusted accordingly in the Ins and Ins+NEFA groups to maintain near-basal levels. At 60 and $120 \mathrm{~min}, 100 \mu \mathrm{l}$ blood samples were taken to measure intermediate levels of plasma insulin and NEFA. At $150 \mathrm{~min}, 250 \mu \mathrm{l}$ blood samples were again taken for measurement of final variables. Adequate anaesthesia was then induced by pentobarbital (40 mg/kg, i.v.) and gastrocnemius muscle was isolated by surgical dissection. Muscle was quickly removed and an aliquot placed in ice-cold $\mathrm{NaCl}$ $0.9 \%$ (wt/vol.) for immediate transfer and analysis. The rest of the tissue was immediately frozen in liquid nitrogen and stored at $-80^{\circ} \mathrm{C}$.

\section{Oxidative stress}

Mitochondrial $\mathrm{H}_{2} \mathrm{O}_{2}$ production ROS production in intact isolated mitochondria was measured by adapting previously described protocols [18]. A sample of fresh tissue was cleaned of connective tissue, placed in buffer $\mathrm{SH}$ (10.5 mmol/l HEPES, $\mathrm{pH}=7.2,250 \mathrm{mmol} / 1$ sucrose,

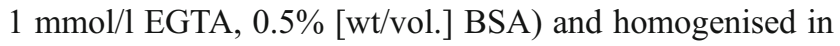
ice. Mitochondria were then isolated by differential centrifugation: myofibrillar fraction was removed $\left(720 \mathrm{~g}, 4^{\circ} \mathrm{C}\right.$, $5 \mathrm{~min})$, and mitochondria were pelleted $\left(10,000 \mathrm{~g}, 4^{\circ} \mathrm{C}\right.$, $5 \mathrm{~min}$ ), washed in buffer $\mathrm{SH}$ and resuspended in buffer $\mathrm{R}$ (20 mmol/1 HEPES, $\mathrm{pH}=7.2,4 \mathrm{mmol} / 1 \mathrm{KH}_{2} \mathrm{PO}_{4}, 1 \mathrm{mmol} / \mathrm{l}$ $\mathrm{MgCl}_{2}, 14 \mathrm{mmol} / \mathrm{l} \mathrm{NaCl}, 125 \mathrm{mmol} / \mathrm{l} \mathrm{KCl}, 20 \mu \mathrm{mol} / \mathrm{l}$ EGTA). An aliquot of the resuspended fraction was frozen at $-80^{\circ} \mathrm{C}$ for measurement of protein content (BCA assay, Pierce, Rockford IL, USA). Concentrated respiratory inhibitors and substrates had been prepared previously, aliquoted and stored at $-80^{\circ} \mathrm{C}$. Working dilutions were prepared immediately before use. The final concentrations in the assay were: carbonyl cyanide $m$-chlorophenyl hydrazone (CCCP; $5 \mu \mathrm{mol} / \mathrm{l})$; antimycin A (AA; $1 \mu \mathrm{g} / \mathrm{ml}) ; 5 \mathrm{mmol} / \mathrm{l}$ pyruvate, $5 \mathrm{mmol} / \mathrm{l}$ malate $(\mathrm{PM}) ; 8 \mathrm{mmol} / 1$ glutamate, $4 \mathrm{mmol} / 1$ malate (GM); $10 \mathrm{mmol} / 1$ succinate (S); $4 \mathrm{mmol} / \mathrm{l}$ glutamate, $2 \mathrm{mmol} / \mathrm{l}$ malate, $10 \mathrm{mmol} / \mathrm{l}$ succinate (GMS); $50 \mu \mathrm{mol} / \mathrm{l}$
palmitoyl-L-carnitine, $2 \mathrm{mmol} / \mathrm{l}$ malate (PCM); $4 \mathrm{mmol} / 1$ glutamate, $8 \mathrm{mmol} / \mathrm{l}$ succinate (GS).

The rate of $\mathrm{H}_{2} \mathrm{O}_{2}$ synthesis in freshly isolated mitochondria was measured by monitoring the conversion of Amplex Red (Invitrogen, Carlsbad, CA, USA) to resorufin using a microplate fluorimeter (Infinite F200, Tecan Group, Switzerland; excitation $535 \mathrm{~nm}$, emission $595 \mathrm{~nm}, 25$ flashes, integration time $20 \mu \mathrm{s})$. Freshly prepared mitochondrial suspension, $20 \mu \mathrm{l}$, was added to a 96 well microplate (Nunc, Rockford, IL, USA). Wells in each row contained $200 \mu \mathrm{l}$ assay buffer $(10 \mu \mathrm{mol} / 1$ Amplex Red, $0.4 \mathrm{U} / \mathrm{ml}$ horseradish peroxidase [HRP], 0.2\% [wt/vol.] BSA in buffer R) and $20 \mu \mathrm{l}$ of ultrapure $\mathrm{H}_{2} \mathrm{O}$, respiration uncoupler (CCCP) or inhibitor (AA). The microplate was incubated for $20 \mathrm{~min}$ at $37^{\circ} \mathrm{C}$. State 4 mitochondrial respiration $\mathrm{H}_{2} \mathrm{O}_{2}$ production was measured after addition, for each row, of $20 \mu \mathrm{l}$ of either ultrapure $\mathrm{H}_{2} \mathrm{O}$ or respiration substrate. Integrity of mitochondrial function was determined by measuring the effects of CCCP and AA, as well as the decrease in $\mathrm{H}_{2} \mathrm{O}_{2}$ synthesis with a third incubation after the addition of $1 \mathrm{mmol} / 1 \mathrm{ADP}$ in each well (state 3 respiration). The rate of $\mathrm{H}_{2} \mathrm{O}_{2}$ synthesis was calculated by interpolation of resorufin fluorescence variation over time with a calibration curve from $\mathrm{H}_{2} \mathrm{O}_{2}$ standards ( $3 \mu \mathrm{mol} / 1$ to $20 \mathrm{nmol} / \mathrm{l}$ ). Data were normalised by sample protein content and expressed as pmol (mg protein $)^{-1} \min ^{-1}$.

Superoxide anion generation Cellular superoxide anion production systems in gastrocnemius lateralis muscle homogenate were assayed combining specific substrates and inhibitors for each source. Detection was performed using the lucigenin chemiluminescence method [19]. Lucigenin concentration in the assay was $10 \mu \mathrm{mol} / 1$ to prevent redox cycling. Briefly, freshly isolated tissue was cleaned of connective tissue and homogenised in ice-cold Krebs-HEPES buffer (20 mmol/l HEPES, $\mathrm{pH}=7.4,99 \mathrm{mmol} / \mathrm{l} \mathrm{NaCl}$, $4.7 \mathrm{mmol} / \mathrm{l} \mathrm{KCl}, 1.2 \mathrm{mmol} / 1 \mathrm{MgSO}_{4}, 1 \mathrm{mmol} / 1 \mathrm{KH}_{2} \mathrm{PO}_{4}$, $1.9 \mathrm{mmol} / 1 \mathrm{CaCl}_{2}, 25 \mathrm{mmol} / 1 \mathrm{NaHCO}_{3}, 11 \mathrm{mmol} / \mathrm{l} \mathrm{D}-\mathrm{glu}-$ cose) with protease inhibitors (Sigma). After centrifugation to remove insoluble debris $\left(240 \times \mathrm{g}, 15 \mathrm{~min}, 4^{\circ} \mathrm{C}\right)$, the suspension was diluted in Krebs-HEPES buffer and lucigenin was added. An $180 \mu$ l volume of the mixture was rapidly transferred to a white 96-well microplate (Nunc). Each well already contained $20 \mu \mathrm{l}$ of either ultrapure $\mathrm{H}_{2} \mathrm{O}$ for sample basal superoxide measurement or the superoxide scavenger tiron $(10 \mathrm{mmol} / \mathrm{l})$ as a negative control and, to test single sources: xanthine $(500 \mu \mathrm{mol} / \mathrm{l})$ with or without the inhibitor oxypurinol $(200 \mu \mathrm{mol} / \mathrm{l})$; NADPH $(1 \mathrm{mmol} / \mathrm{l})$ with or without the inhibitor diphenyleneiodonium $(200 \mu \mathrm{mol} / \mathrm{l})$; the cyclo-oxygenase inhibitor indometacin (100 $\mu \mathrm{mol} / \mathrm{l})$; or the mitochondrial uncoupler CCCP (5 $\mu \mathrm{mol} / \mathrm{l})$. In pilot experiments the concentrations for all substrates and inhibitors were tested, and did not alter luminescence in the 
absence of cellular homogenate. During incubation at $37^{\circ}$ $\mathrm{C}$, from 10 to $30 \mathrm{~min}$, light emission was monitored every $6 \mathrm{~s}$ in a microplate luminometer (Sinergy2, BioTek Instruments, Winooski, VT, USA). To ensure all measurements related to superoxide production, a subsequent reading was performed after addition of tiron to all wells. Samples were run in duplicate. The results were calculated for each well by integration of single light-emission measurements and normalised by protein content in the sample (BCA assay, Pierce). For each source, relative superoxide production was assumed as the difference between basal or, when available, substrate-stimulated production values and the values obtained with the addition of the specific inhibitor.

Glutathione Glutathione is the major buffering system for scavenging ROS, and a shift towards its oxidised form reflects a more oxidised tissue redox state [7]. Total and oxidised glutathione (GSSG) levels were determined in tissue homogenates using the HT Glutathione Assay Kit (Trevigen, Gaithersburg, MD, USA). Briefly, $\sim 50 \mathrm{mg}$ of the gastrocnemius sample was cleaned and homogenised in ice-cold 5\% (wt/vol.) metaphosphoric acid $(20 \mathrm{ml} / \mathrm{g}$ tissue). Homogenates were then centrifuged $(12,000 \times g$ for $15 \mathrm{~min}$ ) and the supernatant fraction was used for total glutathione measurement after appropriate dilution. For oxidised glutathione, samples were pretreated with $2 \mathrm{~mol} / \mathrm{l} 4$ vinylpyridine. Total and GSSG were then measured using the reagents and calibration set provided by the HT Glutathione Assay Kit. Reduced glutathione (GSH) was calculated by subtracting the oxidised fraction from the total.

Protein analysis Total tissue protein was extracted from homogenised tissue as described [20]. Protein concentrations in all samples were measured by spectrophotometer (BCA Protein Assay Reagent, Pierce, Rockford, IL, USA). Total v-akt murine thymoma viral oncogene homologue 1 (AKT), phospho(Ser473)-AKT, total I $\mathrm{BB} \alpha$ and phospho (Ser32)-I $\kappa \mathrm{B} \alpha$ were measured by western blotting using commercially available antibodies (Cell Signaling Technology, Beverly, MA, USA) [20]. Individual results were expressed as percentages of the average values in the control group.

Electrophoretic mobility shift assay Nuclei from rat muscle were prepared with a modified version of previously described methods [21]. Tissue samples were homogenised in a buffered sucrose-salt solution $\left(0.2 \mathrm{mmol} / 1 \mathrm{~K}_{2} \mathrm{HPO}_{4}\right.$, $0.6 \mathrm{mmol} / 1 \mathrm{KH}_{2} \mathrm{PO}_{4}, 0.32 \mathrm{~mol} / \mathrm{l}$ sucrose, $1 \mathrm{mmol} / 1 \mathrm{MgCl}_{2}$, $\mathrm{pH}=6.8$ ) with protease inhibitors (Sigma), nuclei were collected by centrifugation $\left(800 \times \mathrm{g}, 5 \mathrm{~min}, 4^{\circ} \mathrm{C}\right)$ and washed with the same procedure. Myofibrils and mitochondria were removed by prolonged high-speed centrifugation $(16,000 \times g$, $90 \mathrm{~min}, 4^{\circ} \mathrm{C}$ ) after resuspension in high-sucrose buffer $\left(0.2 \mathrm{mmol} / 1 \mathrm{~K}_{2} \mathrm{HPO}_{4}, 0.6 \mathrm{mmol} / 1 \mathrm{KH}_{2} \mathrm{PO}_{4}, 2.15 \mathrm{~mol} / \mathrm{l} \mathrm{su}-\right.$ crose, $1 \mathrm{mmol} / 1 \mathrm{MgCl}_{2}, \mathrm{pH}=6.8$ ). Isolated nuclei were resuspended in $\mathrm{PBS}, \mathrm{pH}=7.4$. Protein content was measured by standard BCA assay (Pierce). Complementary 3'-biotinylated synthetic oligonucleotides containing a high-affinity consensus sequence for NFKB (forward: 5'-AGTTGAGGG GACTTTCCCAGGC-3'-biotin) were annealed by dilution $(50 \mathrm{mmol} / 1 \mathrm{Tris}, \mathrm{pH} 8.0,100 \mathrm{mmol} / \mathrm{l} \mathrm{NaCl})$, heating to $95^{\circ} \mathrm{C}$ for $4 \mathrm{~min}$ and subsequent thermal downramping $\left(0.5^{\circ} \mathrm{C} / \mathrm{min}\right)$ to $20^{\circ} \mathrm{C}$ in a thermocycler (MyCycler, Bio-Rad, Hercules, CA, USA). Incubation for the binding reaction was performed at room temperature for $30 \mathrm{~min}$, after mixing in a reaction volume of $10 \mu \mathrm{l}$, binding buffer (final concentrations: $10 \mathrm{mmol} / \mathrm{l}$ Tris, $\mathrm{pH}=8.0,50 \mathrm{mmol} / \mathrm{l} \mathrm{NaCl}, 1 \mathrm{mmol} / 1$ EDTA, $1 \mathrm{mmol} / 1$ dithiothreitol, $0.05 \%$ [wt/vol.] BSA, $0.05 \%$ [wt/vol.] NP-40, 5\% [wt/vol.] glycerol), $1.5 \mathrm{pmol}$ probe and $50 \mu \mathrm{g}$ of each nuclear protein extract. Polydeoxyinosinicdeoxycytidylic acid $(0.05 \mu \mathrm{g} / \mu \mathrm{l})$ was added for non-specific competition. As a control for the specificity of the bands some samples were incubated in competition with 100 -fold concentration of non-biotinylated probe. Samples were then loaded and run on a continuous $5 \% \mathrm{PAGE}$ at $100 \mathrm{~V}$ and transferred to nylon membrane (Hybond N+, GE Healthcare, Chalfont St Giles, UK) for $2 \mathrm{~h}$ at $380 \mathrm{~mA}$. Both electrophoreses were performed in refrigerated $\times 0.5 \mathrm{TE}$ buffer $(45 \mathrm{mmol} / 1 \mathrm{Tris}$, $45 \mathrm{mmol} / 1$ boric acid, $1 \mathrm{mmol} / \mathrm{l}$ EDTA). Oligomers were cross-linked to the membrane by UV exposure (UVC500, Hoefer, Holliston, MA, USA). After blocking (10 mmol/1 PBS, $\mathrm{pH}=7.4,150 \mathrm{mmol} / \mathrm{l} \mathrm{NaCl}, 0.5 \%$ [wt/vol.] casein, $0.2 \%$ [wt/vol.] SDS) for $1 \mathrm{~h}$ at $37^{\circ} \mathrm{C}$ under gentle shaking, and washing $(10 \mathrm{mmol} / \mathrm{l} \mathrm{PBS}, \mathrm{pH}=7.4,0.1 \%$ [wt/vol.] Tween$20)$, biotin recognition on the membrane was performed by incubation for $30 \mathrm{~min}$ with streptavidin-HRP conjugate (Sigma) in detection buffer (10 mmol/1 PBS, $\mathrm{pH}=7.4,0.1 \%$ [wt/vol.] Casein, $0.1 \%$ [wt/vol.] Tween-20). Following extensive washing and enhanced chemiluminescence (LumiGLO, Cell Signaling, Beverly, MA, USA), membranes were exposed and densitometric analysis was performed.

\section{Mitochondrial function}

Cytochrome c oxidase and citrate synthase activities Cytochrome $c$ oxidase and citrate synthase enzyme activities were measured spectrophotometrically from tissue homogenates as described previously [22].

ATP synthesis ATP synthesis rate was measured on freshly isolated mitochondria as described [23], with slight modifications. Mitochondria were isolated by differential centrifugation as described for the mitochondrial ROS assay, except that buffers A $(50 \mathrm{mmol} / \mathrm{l}$ Tris, $\mathrm{pH} 7.2,100 \mathrm{mmol} / \mathrm{l} \mathrm{KCl}$, 
$5 \mathrm{mmol} / 1 \mathrm{MgCl}_{2}, 1.8 \mathrm{mmol} / \mathrm{l} \mathrm{ATP}, 1 \mathrm{mmol} / \mathrm{l}$ EDTA) and B (225 mmol/1 sucrose, $44 \mathrm{mmol} / 1 \mathrm{KH}_{2} \mathrm{PO}_{4}, 12.5 \mathrm{mmol} / \mathrm{l} \mathrm{Mg}$ $\left(\mathrm{CH}_{3} \mathrm{COO}\right)_{2}, 6 \mathrm{mmol} / 1$ EDTA) were used in place of $\mathrm{SH}$ and $\mathrm{R}$. The efficiency of purification and mitochondrial integrity were confirmed by citrate synthase assays on isolation fractions. Concentrated respiration substrates had been prepared previously, aliquoted and frozen at $-80^{\circ} \mathrm{C}$. Their composition and final reaction concentrations were: $0.25 \mathrm{mmol} / \mathrm{l}$ pyruvate, $12.5 \mu \mathrm{mol} / 1$ palmitoyl-L-carnitine, $2.5 \mathrm{mmol} / \mathrm{l} \alpha$ ketoglutarate, $0.25 \mathrm{mmol} / 1$ malate (PPKM); $25 \mu \mathrm{mol} / \mathrm{l} \mathrm{pal-}$ mitoyl-L-carnitine, $0.5 \mathrm{mmol} / 1$ malate (PCM); $20 \mathrm{mmol} / 1$ succinate, $0.1 \mathrm{mmol} / 1$ rotenone (SR); and $10 \mathrm{mmol} / 1$ glutamate, $5 \mathrm{mmol} / \mathrm{l}$ malate $(\mathrm{GM})$. The ATP synthesis rate was assayed by kinetic measurement of light emission from each well (interval $2 \mathrm{~min}$, integration time $1 \mathrm{~s}$ ) using a microplate luminometer (Synergy 2 SL, BioTek). Each well contained $25 \mu \mathrm{l}$ of diluted sample or ATP standard $(50-0 \mu \mathrm{mol} / \mathrm{l})$ in buffer B, $25 \mu$ l of substrate (PCM, PPKM, SR or GM) and $175 \mu \mathrm{l}$ of assay buffer containing luciferin and luciferase (ATP Reagent SL; BioThema, Handen, Sweden). Finally, $25 \mu \mathrm{l}$ of ADP $1 \mathrm{mmol} / \mathrm{l}$, previously cleared from ATP contamination by glucose/hexokinase incubation, were added in each well to start state 3 respiration. All samples were run in duplicate. $250 \mu \mathrm{g}$ of oligomycin was added to some wells to verify that ATP was generated from mitochondrial respiration. The luciferase-related ATP decrease rate was calculated from standards and used to correct measurement slopes. ATP synthesis rate was then calculated by interpolation of the light emission per min in the linear phase with the ATP standard curve. Measurements obtained were normalised by protein concentration in the mitochondrial fraction preparation, as measured by BCA protein assay (Pierce) and expressed as $\mu \mathrm{mol}$ (mg protein) ${ }^{-1} \mathrm{~min}^{-1}$.

Plasma insulin and NEFA Plasma insulin concentration was measured by radioimmunoassay using a commercially available kit (Linco, St Louis, MO, USA). Plasma NEFA were determined spectrophotometrically (NEFA-C; WAKO Pure Chemical Industries, Osaka, Japan).

Statistical analysis Results in the four groups were compared using one-way ANOVA. Post hoc tests were then used to compare the results of two groups. The paired Student's $t$ test was used to compare results before and following infusions. A $p$ value of $<0.05$ was considered statistically significant.

\section{Results}

Body weight and plasma metabolic profile

Body weights were comparable in the four experimental groups (control $320 \pm 5 \mathrm{~g}$; Ins $314 \pm 2 \mathrm{~g}$; Ins+NEFA $316 \pm 5 \mathrm{~g}$; Ins $+\mathrm{NEFA}+\mathrm{NAC} 320 \pm 4 \mathrm{~g})$. Blood glucose, plasma insulin and NEFA levels were comparable in all groups under basal conditions. The increases in plasma insulin were comparable in the Ins, Ins+NEFA and Ins+NEFA+NAC groups following infusions, while remaining stable in the $\mathrm{NaCl}$-infused control animals (Fig. 1a). No significant differences in blood glucose were observed throughout the study, by design (Fig. 1b). Plasma NEFA levels were not modified by $\mathrm{NaCl}$, but were reduced with Ins as expected. In contrast, lipid infusions with Ins+NEFA and Ins+NEFA+NAC induced similar NEFA elevations compared with both basal and post-infusion values in the control and Ins groups (Fig. 1c).

Insulin-mediated glucose disposal and skeletal muscle insulin signalling

Glucose infusion rate during insulin infusion, normalised for time and body weight, reflects whole-body insulin-stimulated glucose disposal and is therefore an accurate index of insulin sensitivity. Insulin sensitivity at the whole-body level was markedly lower in the Ins+NEFA group than in the Ins group (Fig. 2a). Ins stimulated AKT phosphorylation in muscle as expected, but the increment was less pronounced during Ins +NEFA infusion, indicating lipid-induced insulin resistance (Fig. 2b). Antioxidant infusion in the Ins+NEFA+NAC group completely prevented NEFA-induced alterations (Fig. 2a, b).

Skeletal muscle mitochondrial ROS generation, superoxide production and GSSG-GSH levels

No effects of insulin per se were observed on ROS generation at the mitochondrial level (Fig. $3 \mathrm{a}-\mathrm{c}$ ) or through potential nonmitochondrial sources NADPH oxidase and cyclooxygenase (Fig. 3d). Ins, however, enhanced muscle superoxide production selectively through the xanthine oxidase pathway (Fig. 3d). The above effect was associated with an increase in the oxidised-to-reduced glutathione (GSSG/GSH) ratio (Fig. 4c). Muscle mitochondrial ROS generation was markedly higher in the Ins+NEFA group compared with other experimental groups (Fig. 3a-c). Compared with controls, a moderate increase in superoxide production through the xanthine oxidase pathway was observed also for the Ins+NEFA group, although it remained markedly lower than the one induced by hyperinsulinaemia per se (Fig. 3d). Changes in Ins+NEFA were associated with markedly higher GSSG/GSH ratio compared with both control and Ins groups (Fig. 4c). Concomitant NAC infusion with insulin and NEFA normalised mitochondrial ROS production (Fig. 3a-c) and the GSSG/GSH ratio (Fig. 4c).

I $\kappa \mathrm{B} \alpha$ subunit and $\mathrm{NF} \kappa \mathrm{B}-\mathrm{DNA}$ interaction

Changes in ROS production are reported to be associated with activation of the I $\kappa \mathrm{B}-\mathrm{NF} \kappa \mathrm{B}$ proinflammatory pathway through IkB phosphorylation and subsequent degradation, 

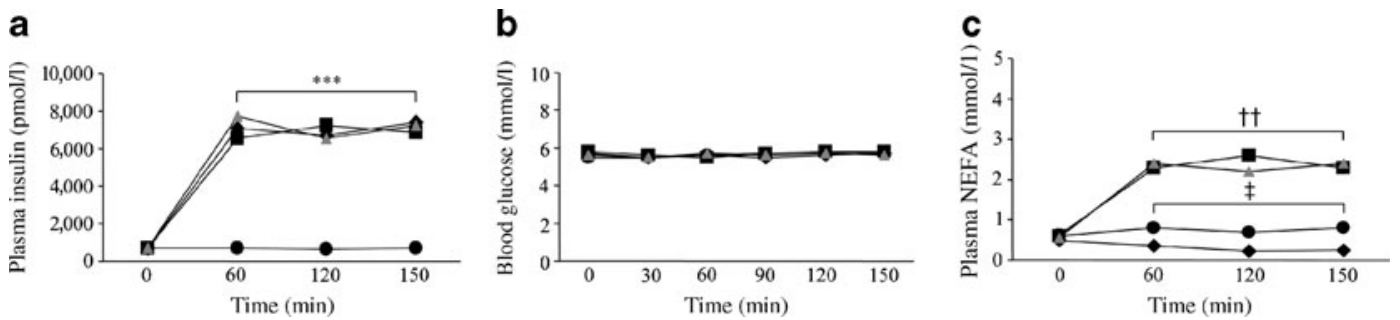

Fig. 1 Effects of control (circles), Ins (diamonds), Ins+NEFA (triangles) and Ins+NEFA+NAC (squares) on plasma insulin (a), blood glucose (b), and plasma NEFA (c). ${ }^{* * *} p<0.001$ Ins, Ins + NEFA and Ins + NEFA+NAC vs Control; ${ }^{\dagger \dagger} p<0.01$ vs Control and Ins; ${ }^{*} p<0.05$ Control vs all other groups

NFkB nuclear translocation and DNA binding. Also, importantly, these changes reflect upstream reactions that directly impair insulin signalling. In the current study, Ins did not alter either IKB phosphorylated-to-total ratio (P/T ratio; Fig. 5a) or NFKB-DNA interaction (Fig. 5b). Conversely, the NEFA-induced higher mitochondrial ROS production was associated with both higher $\mathrm{P} / \mathrm{T}$ I $\mathrm{KB}$ and $\mathrm{NF} \kappa \mathrm{B}-\mathrm{DNA}$ interaction, and these alterations were prevented by antioxidant infusion (Fig. 5a, b).

Mitochondrial enzyme activities and ATP production

Activities of cytochrome $c$ oxidase and citrate synthase were not statistically significantly different in any group (Fig. 6a, b). Mitochondrial ATP production rate was not impaired in the presence of enhanced ROS generation but was, instead, enhanced in both NEFA-infused groups compared with controls (Fig. 6c).

\section{Discussion}

The major findings of this study are that: (1) hyperinsulinaemia in the high physiological range causes a shift towards a more oxidised redox state in rat skeletal muscle in vivo, selectively associated with enhanced

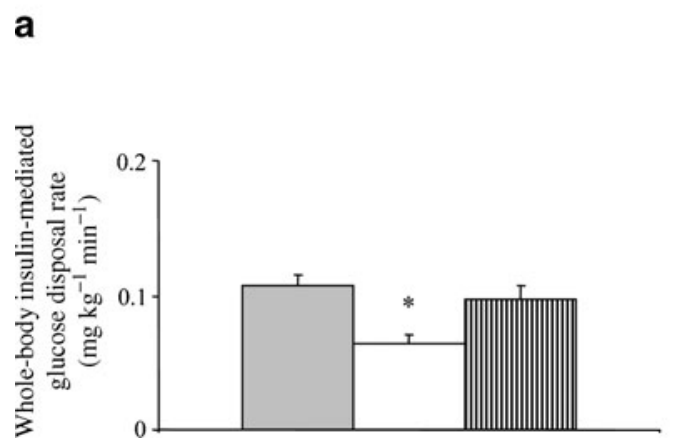

Fig. 2 Whole-body insulin-mediated glucose disposal (glucose infusion rate in the last $30 \mathrm{~min}$ of hyperinsulinaemic-euglycaemic clamps) (a) and gastrocnemius muscle P/T-AKT ratio in the four experimental groups (b). Black bars, control; grey bars, Ins; white bars, Ins+NEFA;
ROS production at the xanthine oxidase level; (2) concomitant NEFA elevation lowers insulin action, in association with enhanced muscle ROS production at the mitochondrial level and IKB-NFKB activation; (3) NEFA-induced metabolic alterations are prevented by antioxidant infusion and are therefore caused by their mitochondrial pro-oxidant effects with $\mathrm{I} \kappa \mathrm{B}-\mathrm{NF} \kappa \mathrm{B}$ involvement; (4) acute changes in muscle mitochondrial ROS production, redox state and insulin signalling are not associated with impaired tissue mitochondrial function under the current experimental conditions.

The current study introduces the concept that prooxidative modulation of the muscle redox state is a physiological effect of insulin in vivo. Insulin had been reported to enhance the generation of ROS in adipose and liver cells in vitro $[1,2]$, with involvement of NADPH oxidase and no negative impact on insulin signalling $[1,2]$. The current data show that pro-oxidant insulin-induced changes in superoxide production and redox state are, however, not associated with proinflammatory changes in skeletal muscle of lean animals in the absence of concomitant NEFA elevation. These findings are therefore consistent with previous reports indicating that insulin-induced oxidative stress per se has no major negative metabolic effects and does not activate major insulin-desensitising metabolic pathways in non-muscle tissues [1-4]. Under the current conditions, the data also

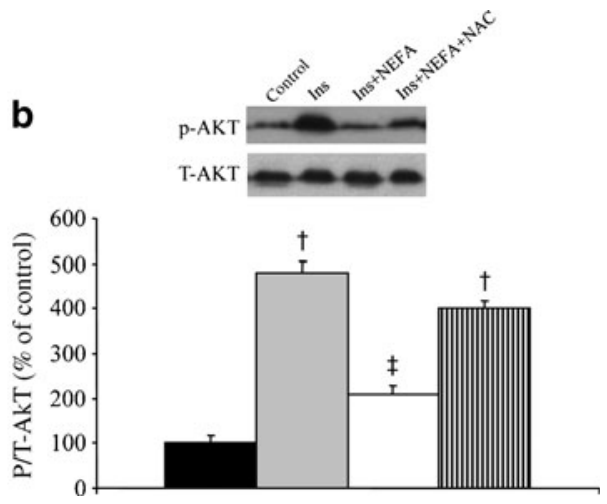

hatched bars, Ins+NEFA+NAC. Representative bands from the four experimental groups are shown in (b). ${ }^{*} p<0.05$ vs Ins and Ins+NEFA+NAC; ${ }^{\dagger} p<0.05$ vs Control and Ins + NEFA, $\vdots p<0.05$ vs all other groups 

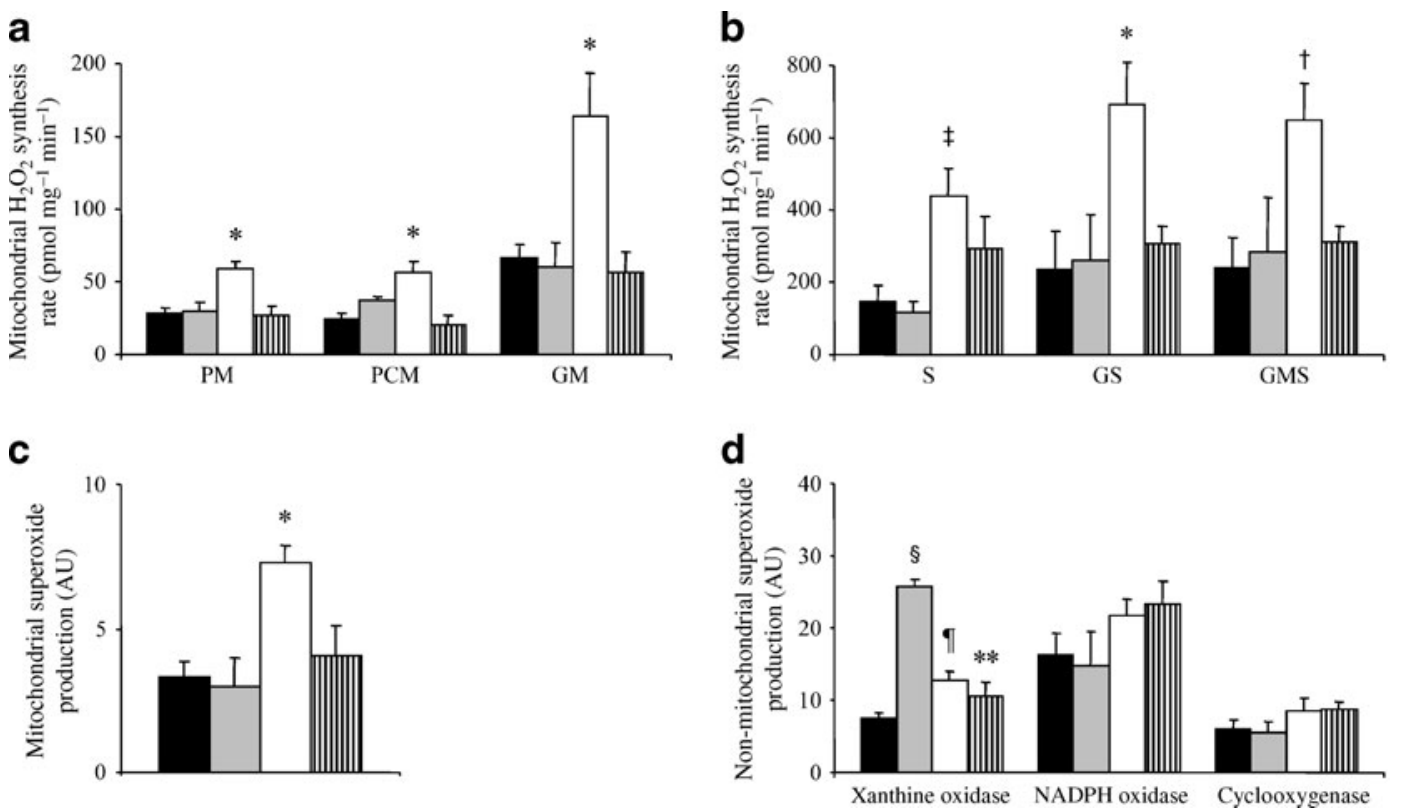

Fig. 3 a, b Mitochondrial $\mathrm{H}_{2} \mathrm{O}_{2}$ generation measured during respiration with different substrate combinations: (a) PM, PCM and GM; and (b) S, GS, GMS. c Mitochondrial superoxide production (by CCCP inhibition). d Superoxide generation from non-mitochondrial xanthine oxidase (oxypurinol inhibition of xanthine-induced synthesis), $\mathrm{NADPH}$ oxidase (diphenyleneiodonium inhibition of NADPH-

identify xanthine oxidase as a selective non-mitochondrial source mediating insulin-induced superoxide production, and this finding is intriguing as it introduces a novel link between insulin, oxidative stress and the xanthine oxidase pathway. Additional studies should be specifically designed to investigate potential interactions between insulin, xanthine oxidase and insulin signalling in models of chronic oxidative stress characterised by insulin resistance and hyperinsulinaemia.

induced synthesis) and cyclooxygenase (indometacin inhibition). ${ }^{*} p<0.05$ vs control, Ins and Ins+NEFA+NAC; ${ }^{\dagger} p<0.05$ vs control and Ins+NEFA+NAC; ${ }^{\ddagger} p<0.05$ vs control and Ins; ${ }^{8} p<0.05$ vs control, Ins $+\mathrm{NEFA}$, Ins+NEFA+NAC; ${ }^{\top} p<0.05$ vs Control and Ins; ${ }^{* *} p<0.05$ vs Ins. Black bars, control; grey bars, Ins; white bars, Ins+NEFA; hatched bars, Ins+NEFA+NAC. AU, arbitrary units

Fatty acid elevation profoundly modulated muscle insulin effects, leading to lower insulin signalling activation associated with selective enhancement of mitochondrial ROS production, pro-oxidative changes in tissue redox state and activation of the IKB-NFKB proinflammatory pathway. The different metabolic impact of quantitatively different levels of ROS production, such as those observed during insulin infusion with and without NEFA, is consistent with previously reported differential effects of low and high

Fig. 4 Gastrocnemius muscle reduced glutathione (GSH) (a), oxidised glutathione (GSSG) (b) and GSSG/GSH ratio (c) in the four experimental groups: control (black bars); Ins (grey bars); Ins+NEFA (white bars); and Ins $+\mathrm{NEFA}+\mathrm{NAC}$ (hatched bars). ${ }^{*} p<0.05$ vs control, Ins and Ins+NEFA+NAC; ${ }^{\dagger} p<0.05$ vs Control; $* * p<0.01$ vs control and Ins+NEFA; ${ }^{\dagger} p<0.01$ vs control, Ins and Ins + $\mathrm{NEFA}+\mathrm{NAC}$ a
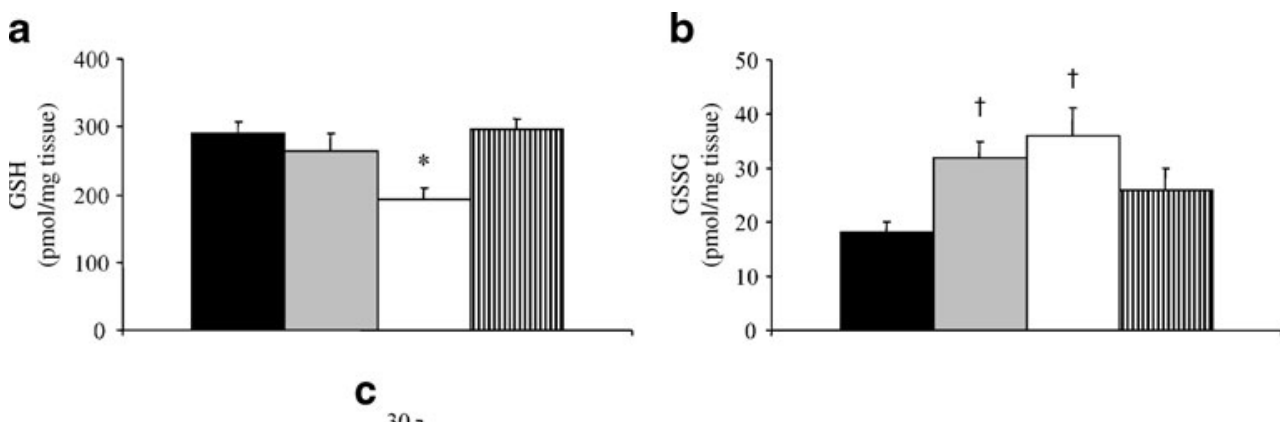

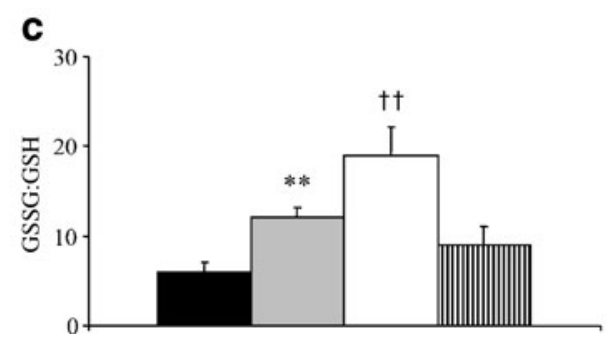


Fig. 5 Gastrocnemius muscle $\mathrm{P} / \mathrm{T}-\mathrm{I} \kappa \mathrm{B} \alpha$ protein $(\mathbf{a})$ and NFkBDNA binding activity (b) in the four experimental groups: control (black bars); Ins (grey bars); Ins+NEFA (white bars); and Ins+NEFA+NAC (hatched bars). ${ }^{*} p<0.05$ vs other groups. p-IкB $\alpha$, phosphorylated IкB $\alpha$;

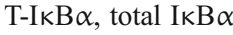

a
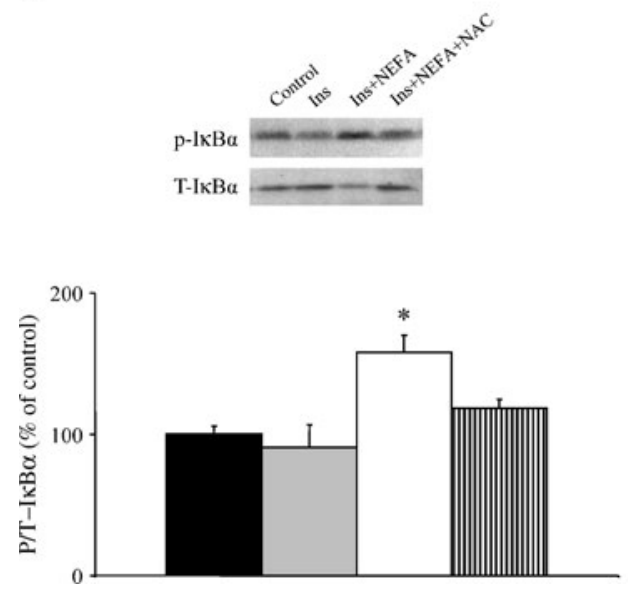

b
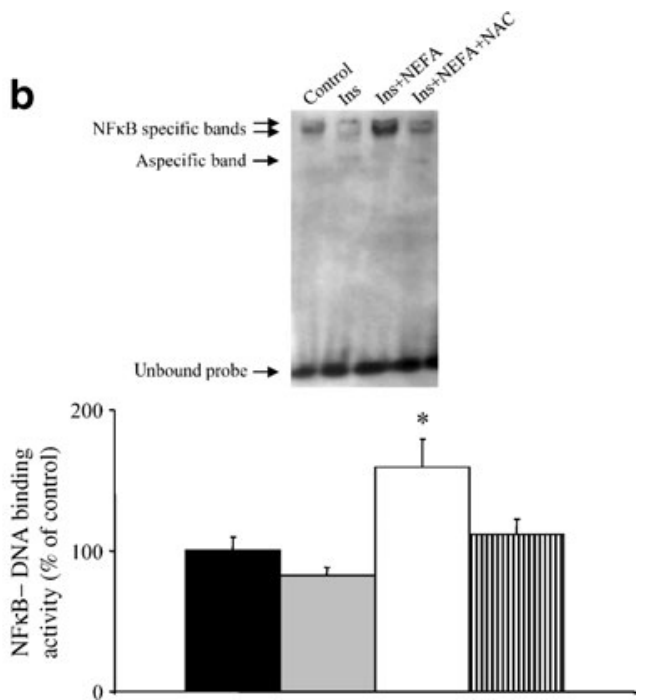

levels of ROS on key physiological muscle functions, such as contractile strength and sarcoplasmic reticulum calcium release [24]. In addition, the possibility that different sites and pathways of ROS production have different effects on muscle metabolic pathways cannot be excluded. Overall, the data identify a novel cluster of NEFA-induced muscle metabolic alterations in the presence of physiological hyperinsulinaemia. Also importantly, concomitant infusion of the antioxidant ROS scavenger NAC prevented the above changes. This observation provides direct evidence for a causal role of mitochondrial ROS production and oxidative stress in the onset of fatty-acid-induced muscle insulin resistance with involvement of the I $\kappa \mathrm{B}-\mathrm{NF} \kappa \mathrm{B}$ pathway, the activation of which by ROS has been previously reported under different experimental conditions [8].

It should be pointed out that the current experiments were designed to investigate insulin-fatty acid interactions, and the observed metabolic effects cannot be assumed to extend to conditions of isolated fatty acid elevation. Independent effects of fatty acids on muscle redox state are, however, also supported by in vitro studies $[9,10]$. Moreover, the current conditions have direct pathophysiological implications in the postprandial state, when hyperinsulinaemia is associated with variable changes in plasma NEFA concentration depending on meal composition [7, 25]. Fatty acid elevation in our study is indeed comparable with reported peak fatty acid increments following fatty meals in humans [25], suggesting that elevated fatty acid availability following ingestion of a fatty meal may directly cause muscle oxidative stress and inflammation, leading to acute insulin resistance. Importantly, less pronounced elevations of plasma insulin and NEFA concentrations are also observed in obesity induced by long-term high-fat feeding. A contribution of fatty acids to oxidative stress and inflammation
Fig. 6 Gastrocnemius muscle cytochrome $c$ oxidase (a) and citrate synthase (b) enzyme activities. c ATP production rate using different substrate combinations. Black bars, control; Ins, grey bars; white bars, Ins+NEFA; hatched bars, Ins+NEFA+NAC. $* p<0.05$ vs Control; ${ }^{\dagger} p<0.05$ vs control and Ins

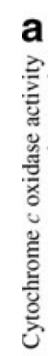

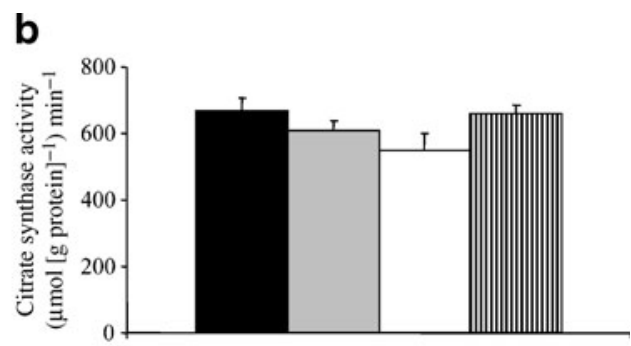

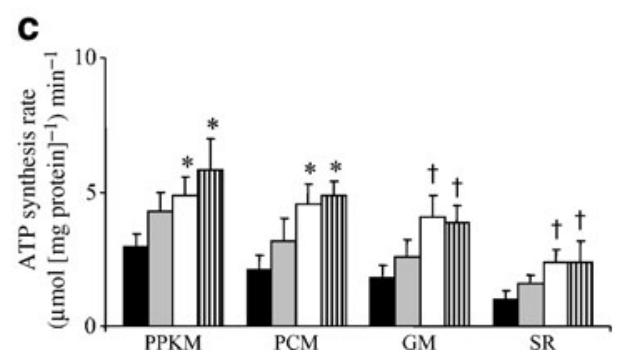


previously reported under the above conditions is suggested by the current results $[7,13,14]$, but the direct investigation of this will require further studies with less pronounced and more sustained fatty acid elevation.

Although the issue is partly controversial, chronic changes in mitochondrial oxidative capacity and function have been proposed to contribute to modulation of muscle insulin action by regulating lipid oxidative use $[15,26]$. Oxidative stress and proinflammatory cytokines were also reported to lower markers of muscle mitochondrial content and function in the context of chronic high-fat feeding [13, 14]. The current study, however, demonstrated that acute peak physiological fatty acid elevation does not impair mitochondrial enzyme activities or ATP production, which can instead be enhanced by higher lipid substrate availability even in the presence of enhanced ROS production. While this last finding is consistent with a recent study showing that high ROS production in ageing human skeletal muscle is not associated with impaired mitochondrial respiration [27], the current results support the view that the onset of insulin resistance is, at least in part, independent of the inhibition of mitochondrial enzyme activities and ATP production capacity [27].

In summary, the current findings demonstrate that acute insulin elevation in the physiological range induces prooxidative changes in muscle redox state through the nonmitochondrial xanthine oxidase pathway. This novel insulin effect does not, however, appear to lead to major negative metabolic effects in the absence of simultaneous NEFA elevation. On the other hand, further enhancement of ROS production at the mitochondrial level by fatty acid infusion causes muscle and systemic insulin resistance through activation of the IKB-NFkB pathway. These changes could play a key role in the negative impact of NEFA on insulin action following fat ingestion, and potentially in the onset of obesityassociated metabolic alterations. Acute changes in muscle mitochondrial ROS production, redox state and insulin signalling are not associated with impaired tissue mitochondrial function under the current experimental conditions.

\begin{abstract}
Acknowledgements The study was supported in part by a fellowship to R. Barazzoni from the European Society for Clinical Nutrition and Metabolism (ESPEN). The authors gratefully acknowledge the skilful assistance of G. Cadelli, M. Stebel and P. Zarattini (Animal Facility, University of Trieste) in rat vein and artery cannulation, and of M. de Nardo and L. Mamolo (Clinica Medica, Department of Medical, Surgical and Health Sciences) in performing infusion experiments. Assistance from G. Lunazzi (Clinica Medica, Department of Medical, Surgical and Health Sciences) in performing some western blotting experiments is also acknowledged.
\end{abstract}

Contribution statement RB was involved in the conception and design of the study, data interpretation and drafting and revision of the article; MZ contributed to data interpretation and revision of the article; GGC was involved in data analysis and interpretation and revision of the article; AS contributed to data analysis and interpretation, and revision of the article; $\mathrm{MB}$ was involved in data analysis, and revision of the article; EC was involved in data analysis, and revision of the article; AP contributed to data analysis, and revision of the article; LC was involved in data analysis and revision of the article; GG contributed to interpretation of data, revising the article. All authors approved the final version to be published.

Duality of interest The authors declare that there is no duality of interest associated with this manuscript.

\section{References}

1. Meng TC, Buckley DA, Galic S, Tiganis T, Tonks NK (2004) Regulation of insulin signaling through reversible oxidation of the protein-tyrosine phosphatases TC45 and PTP1B. J Biol Chem 279:37716-37725

2. Mahadev K, Motoshima H, Wu X et al (2004) The NAD(P)H oxidase homolog Nox4 modulates insulin-stimulated generation of $\mathrm{H}_{2} \mathrm{O}_{2}$ and plays an integral role in insulin signal transduction. Mol Cell Biol 24:1844-1854

3. Goldstein BJ, Mahadev K, Wu X (2005) Redox paradox: insulin action is facilitated by insulin-stimulated reactive oxygen species with multiple potential signaling targets. Diabetes 54:311-321

4. Loh K, Deng H, Fukushima A et al (2009) Reactive oxygen species enhance insulin sensitivity. Cell Metab 10:260-272

5. Urakawa H, Katsuki A, Sumida Y et al (2003) Oxidative stress is associated with adiposity and insulin resistance in men. J Clin Endocrinol Metab 88:4673-4676

6. Furukawa S, Fujita T, Shimabukuro M et al (2004) Increased oxidative stress in obesity and its impact on metabolic syndrome. J Clin Invest 114:1752-1761

7. Anderson EJ, Lustig ME, Boyle KE et al (2009) Mitochondrial $\mathrm{H}_{2} \mathrm{O}_{2}$ emission and cellular redox state link excess fat intake to insulin resistance in both rodents and humans. J Clin Invest 119:573-581

8. Wei Y, Sowers JR, Clark SE, Li W, Ferrario CM, Stump CS (2008) Angiotensin II-induced skeletal muscle insulin resistance mediated by NF-kappaB activation via NADPH oxidase. Am J Physiol Endocrinol Metab 294:E345-E351

9. Rachek LI, Musiyenko SI, LeDoux SP, Wilson GL (2007) Palmitate induced mitochondrial deoxyribonucleic acid damage and apoptosis in 16 rat skeletal muscle cells. Endocrinology 148:293299

10. Yuzefovych L, Wilson G, Rachek L (2010) Different effects of oleate vs palmitate on mitochondrial function, apoptosis, and insulin signaling in L6 skeletal muscle cells: role of oxidative stress. Am J Physiol Endocrinol Metab 299:E1096-E1105

11. Boden G, Shulman GI (2002) Free fatty acids in obesity and type 2 diabetes: defining their role in the development of insulin resistance and beta-cell dysfunction. Eur J Clin Invest 32(Suppl 3):14-23

12. Han DH, Hancock C, Jung SR, Holloszy JO (2009) Is "fat-induced" muscle insulin resistance rapidly reversible? Am J Physiol Endocrinol Metab 297:E236-E241

13. Bonnard C, Durand A, Peyrol S et al (2008) Mitochondrial dysfunction results from oxidative stress in the skeletal muscle of dietinduced insulin-resistant mice. J Clin Invest 118:789-800

14. Valerio A, Cardile A, Cozzi V et al (2006) TNF-alpha downregulates eNOS expression and mitochondrial biogenesis in fat and muscle of obese rodents. J Clin Invest 116:2791-2798

15. Morino K, Petersen KF, Shulman GI (2006) Molecular mechanisms of insulin resistance in humans and their potential links with mitochondrial dysfunction. Diabetes 55(Suppl 2):S9-S15 
16. Kim YI, Lee FN, Choi WS, Lee S, Youn JH (2006) Insulin regulation of skeletal muscle PDK4 mRNA expression is impaired in acute insulin-resistant states. Diabetes 55:2311-2316

17. Haber CA, Lam TK, Yu Z et al (2003) $N$-acetylcysteine and taurine prevent hyperglycemia-induced insulin resistance in vivo: possible role of oxidative stress. Am J Physiol Endocrinol Metab 285: E744-E753

18. Starkov AA (2010) Measurement of mitochondrial ROS production. Methods Mol Biol 648:245-255

19. Guzik TJ, Channon KM (2005) Measurement of vascular reactive oxygen species production by chemiluminescence. Methods Mol Med 108:73-89

20. Barazzoni R, Zanetti M, Cattin MR et al (2007) Ghrelin enhances in vivo skeletal muscle but not liver AKT signaling in rat. Obesity 15:2614-2623

21. Edelman JC, Edelman PM, Kniggee KM, Schwartz IL (1965) Isolation of skeletal muscle nuclei. J Cell Biol 27:365-377

22. Barazzoni R, Zanetti M, Bosutti A et al (2005) Moderate caloric restriction, but not physiological hyperleptinemia per se, enhances mitochondrial oxidative capacity in rat liver and skeletal muscletissue-specific impact on tissue triglyceride content and AKT activation. Endocrinology 146:2098-2106

23. Lanza IR, Nair KS (2009) Functional assessment of isolated mitochondria in vitro. Methods Enzymol 457:349-372

24. Lecarpentier Y (2007) Physiological role of free radicals in skeletal muscles. J Appl Physiol 103:1917-1918

25. Varela LM, Ortega A, Bermudez B et al (2011) A high-fat meal promotes lipid-load and apolipoprotein B-48 receptor transcriptional activity in circulating monocytes. Am J Clin Nutr 93:918925

26. Hancock CR, Han DH, Chen M et al (2008) High-fat diets cause insulin resistance despite an increase in muscle mitochondria. Proc Natl Acad Sci USA 105:7815-7820

27. Lefort N, Glancy B, Bowen B et al (2010) Increased reactive oxygen species production and lower abundance of complex I subunits and carnitine palmitoyltransferase 1B protein despite normal mitochondrial respiration in insulin-resistant human skeletal muscle. Diabetes 59:2444-2452 